\title{
Maternal Urinary Metal and Metalloid Concentrations in Association with Oxidative Stress Biomarkers
}

\author{
Pahriya Ashrap ${ }^{1}$, Deborah J. Watkins ${ }^{1}$, Ginger L. Milne ${ }^{2}$, Kelly K. Ferguson ${ }^{3}$, Rita Loch-Caruso ${ }^{1}$, \\ Jennifer Fernandez ${ }^{1}{ }^{(D)}$, Zaira Rosario ${ }^{4}$, Carmen M. Vélez-Vega ${ }^{5}$, Akram Alshawabkeh ${ }^{6}$, José F. Cordero ${ }^{4}$ (D) \\ and John D. Meeker ${ }^{1, *}$
}

1 Department of Environmental Health Sciences, University of Michigan School of Public Health, Ann Arbor, MI 48109, USA; pahriya@umich.edu (P.A.); debjwat@umich.edu (D.J.W.); rlc@umich.edu (R.L.-C.); jafernan@umich.edu (J.F.)

2 Vanderbilt University Medical Center, Division of Clinical Pharmacology, Nashville, TN 37232, USA; ginger.milne@vumc.org

3 Epidemiology Branch, National Institute of Environmental Health Sciences, Research Triangle Park, North Carolina, NC 27709, USA; kelly.ferguson2@nih.gov

4 Department of Epidemiology and Biostatistics, University of Georgia, Athens, GA 30602, USA; zaira.rosario@upr.edu (Z.R.); jcordero@uga.edu (J.F.C.)

5 UPR Medical Sciences Campus, University of Puerto Rico Graduate School of Public Health, San Juan, PR 00921, USA; carmen.velez@upr.edu

6 College of Engineering, Northeastern University, Boston, MA 02115, USA; a.alshawabkeh@northeastern.edu

* Correspondence: meekerj@umich.edu; Tel.: +1-734-764-7184

Citation: Ashrap, P.; Watkins, D.J.; Milne, G.L.; Ferguson, K.K.; Loch-Caruso, R.; Fernandez, J.; Rosario, Z.; Vélez-Vega, C.M.; Alshawabkeh, A.; Cordero, J.F.; et al. Maternal Urinary Metal and Metalloid Concentrations in Association with Oxidative Stress Biomarkers. Antioxidants 2021, 10, 114. https://doi.org/10.3390/antiox 10010114

Received: 18 December 2020 Accepted: 12 January 2021 Published: 15 January 2021

Publisher's Note: MDPI stays neutral with regard to jurisdictional clai$\mathrm{ms}$ in published maps and institutional affiliations.

Copyright: (C) 2021 by the authors. Licensee MDPI, Basel, Switzerland. This article is an open access article distributed under the terms and conditions of the Creative Commons Attribution (CC BY) license (https:// creativecommons.org/licenses/by/ $4.0 /)$.

\begin{abstract}
Metal exposure has been associated with a wide range of adverse birth outcomes and oxidative stress is a leading hypothesis of the mechanism of action of metal toxicity. We assessed the relationship between maternal exposure to essential and non-essential metals and metalloids in pregnancy and oxidative stress markers, and sought to identify windows of vulnerability and effect modification by fetal sex. In our analysis of 215 women from the PROTECT birth cohort study, we measured 14 essential and non-essential metals in urine samples at three time points during pregnancy. The oxidative stress marker 8-iso-prostaglandin F2 $\alpha$ (8-iso-PGF2 $\alpha$ ) and its metabolite 2,3-dinor-5,6-dihydro-15-15-F2t-IsoP, as well as prostaglandin F2 $\alpha$ (PGF2 $\alpha$ ), were also measured in the same urine samples. Using linear mixed models, we examined the main effects of metals on markers of oxidative stress as well as the visit-specific and fetal sex-specific effects. After adjustment for covariates, we found that a few urinary metal concentrations, most notably cesium (Cs) and copper $(\mathrm{Cu})$, were associated with higher 8-iso-PGF2 $\alpha$ with effect estimates ranging from 7.3 to $14.9 \%$ for each interquartile range, increase in the metal concentration. The effect estimates were generally in the same direction at the three visits and a few were significant only among women carrying a male fetus. Our data show that higher urinary metal concentrations were associated with elevated biomarkers of oxidative stress. Our results also indicate a potential vulnerability of women carrying a male fetus.
\end{abstract}

Keywords: metals; isoprostane; biomarkers; oxidative stress; Puerto Rico

\section{Introduction}

Metals are environmental contaminants with the potential to impact biological pathways that contribute to preterm delivery [1-5]. One of the leading proposed mechanisms for metal toxicity is oxidative stress, defined as the homeostatic imbalance between cellular oxidants and availability of antioxidants to favor oxidation [6]. Oxidative stress plays an important role in the development of many adverse birth outcomes, including preeclampsia, preterm birth, and intrauterine growth restriction [7-11]. The levels of oxidative stress biomarkers, such as 8-iso-prostaglandin F2 $\alpha$ (8-iso-PGF2 $\alpha$ ), increase during pregnancy and peak at delivery [12], suggesting that this mechanism plays an important role in normal 
childbirth. Previous human studies have shown positive associations between higher levels of oxidative stress biomarkers (8-iso-PGF2 $\alpha$ ) and preterm birth [13-17]. A recent analysis in the Puerto Rico Testsite for Exploring Contamination Threats (PROTECT) cohort study also suggested that elevated levels of 8-iso-PGF2 $\alpha$ and its metabolite are associated with higher odds of overall preterm birth and particularly spontaneous preterm birth [18].

Several in vivo and in vitro studies have linked metal exposure with increased formation of reactive oxygen species (ROS) $[19,20]$. The excessive ROS can induce oxidative stress and cause damage to cells, leading to the release of lipid peroxidation products into circulation [21]. Elevated biomarkers of oxidative stress in association with exposure to heavy metals, including lead (Pb), arsenic (As), and cadmium (Cd), have been reported [22-26]. These non-essential metals have no known physiologic role in the human body and can be toxic if present even at low concentrations $[1,27,28]$. Moreover, they have been associated with preterm birth in epidemiological studies [29-37], including studies in the PROTECT cohort, where $\mathrm{Pb}$, even at low-levels, was the most strongly associated with risk of preterm birth [38]. However, essential metals, such as copper ( $\mathrm{Cu})$, iron (Fe), manganese (Mn), molybdenum (Mo), selenium (Se), and zinc ( $\mathrm{Zn})$, which are important for human health, as well as other metals, such as cesium (Cs) and antimony (Sb), that are not classified as essential or non-essential, remain understudied [39,40]. Most metals, including essential metals, are redox-active and therefore have the potential to increase production of ROS and enhance lipid peroxidation $[41,42]$. To our knowledge, two prior studies explored the direct effects of essential and non-essential trace metals on oxidative stress biomarkers during pregnancy $[26,43]$. Dashner-Titus et al. reported that As is associated with increased levels of urinary 8-iso-PGF2 $\alpha$ [26] and Kim et al. found positive associations of urinary Se and $\mathrm{Cu}$ with oxidative stress markers [43]. Whereas both prior studies were cross-sectional, the PROTECT study provided an opportunity to explore the longitudinal effect of various essential and non-essential metals on oxidative stress. The objective of this study was to explore the association between urinary metals and oxidative stress biomarkers, as well to identify windows of vulnerability and effect modification by fetal sex, by utilizing repeated measures of biomarkers among pregnant women participating in PROTECT.

\section{Materials and Methods}

\subsection{Study Population}

This study used data collected from women participating in the PROTECT study, an ongoing, prospective birth cohort [44-47]. The PROTECT study launched in 2010 with funding from the National Institute of Environmental Health Sciences (NIEHS) Superfund Research Program and is conducted in Puerto Rico because of its high preterm birth rate and the extent of hazardous waste contamination on the island. PROTECT aims to explore environmental exposures and other factors contributing to preterm birth risk and other adverse birth outcomes in Puerto Rico.

Study participants were recruited at approximately $14 \pm 2$ weeks of gestation at seven prenatal clinics and hospitals throughout Northern Puerto Rico and followed until delivery $[44,45]$. Inclusion criteria for this study were: maternal age between 18 and 40 years; residence inside of the Northern Karst aquifer region; disuse of oral contraceptives during the three months prior to pregnancy; disuse of in vitro fertilization to become pregnant; and free of any major medical or obstetrical complications, including pre-existing conditions, such as diabetes, hypertension, etc. Each woman participated in a total of up to three study visits (18 \pm 2 weeks, $22 \pm 2$ weeks, and $26 \pm 2$ weeks of gestation). Detailed information on medical and pregnancy history were collected at the initial visit. During an in-home visit (second visit), nurse-administered questionnaires were used to gather information on housing characteristics, employment status, and family situation. Spot urine samples were collected from women at up to three visits. The present analysis reflects 337 urine samples from 215 women with measured metal(loid) and oxidative stress biomarker concentrations (Figure 1). 
The research protocol was approved by the Ethics and Research Committees of the University of Puerto Rico and participating clinics, the University of Michigan, Northeastern University, and the University of Georgia (Approval number: A8570110). The study was described in detail to all participants, and informed consent was obtained prior to study enrollment.

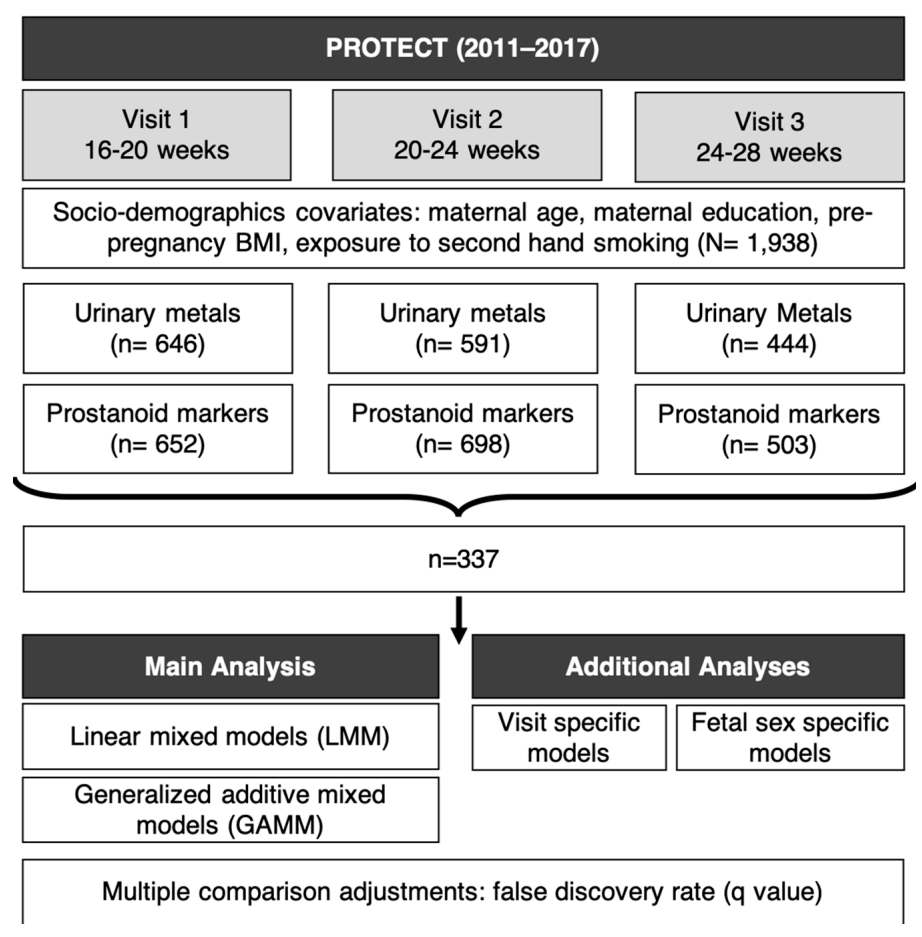

Figure 1. Schematic plot for PROTECT cohort study design, sample size, and statistical methods.

\subsection{Measurement of Metals}

Spot urine was collected in sterile polypropylene cups and aliquoted within one hour after collection. All samples were frozen and stored at $-80{ }^{\circ} \mathrm{C}$ and shipped on dry ice. Analysis was performed at NSF International (Ann Arbor, MI, USA), where concentrations of 21 metals and metalloids were measured: Arsenic (As), barium (Ba), beryllium (Be), cadmium (Cd), cobalt (Co), chromium (Cr), cesium (Cs), copper $(\mathrm{Cu})$, mercury $(\mathrm{Hg})$, manganese $(\mathrm{Mn})$, molybdenum $(\mathrm{Mo})$, nickel $(\mathrm{Ni})$, lead $(\mathrm{Pb})$, platinum $(\mathrm{Pt}), \mathrm{Sb}$, tin $(\mathrm{Sn})$, titanium (Ti), tungsten (W), uranium (U), vanadium (V), and zinc (Zn). Metal(loid) concentrations were measured using inductively-coupled plasma mass spectrometry (ICPMS) as described previously [48]. Considering that biological samples have high levels of carbon and chloride in the matrix, the laboratory selected the appropriate isotopes for the requested elements to best avoid interferences where possible. The ICPMS was calibrated with a blank and a minimum of four standards for each element of interest. An $R^{2}$ value of $>0.995$ was the minimum criteria for an acceptable calibration curve. The calibration curves were verified by initial checks at three calibration points within the curve. Continuing calibration checks and blanks after every 10 samples were also utilized throughout the analytical run to ensure the ICPMS system was maintaining acceptable performance. Urinary specific gravity was measured at the University of Puerto Rico Medical Sciences Campus using a hand-held digital refractometer (Atago Co., Ltd., Tokyo, Japan) as an indicator of urine dilution.

\subsection{Measurement of Oxidative Stress Biomarkers}

Urine samples were collected in polypropylene containers, divided into aliquots, and frozen at $-80{ }^{\circ} \mathrm{C}$ until analysis [47]. To assess oxidative stress, the following prostanoids were measured in urine samples: 8 -iso-PGF2 $\alpha$, the 8-iso-PGF2 $\alpha$ major metabolite 2,3- 
dinor-5,6-dihydro-15-15-F2t-IsoP, and PGF2 $\alpha$. Analyses were performed by the Eicosanoid Core Laboratories at the Vanderbilt University Medical Center (Nashville, TN, USA). All three prostanoids were quantified using the GC/NICI-MS on an Agilent 5973 inert mass selective detector that is coupled with an Agilent 6890n Network GC system (Agilent Labs, Torrance, CA, USA) [49-51]. The precision of this assay in biological fluids is $+6 \%$ and the accuracy is $94 \%$. Further details describing the measurement of oxidative stress biomarker concentrations are available elsewhere [51].

Although 8-iso-PGF2 $\alpha$ has been used as a biomarker of oxidative stress and its release attributed to chemical (nonenzymatic) lipid peroxidation [52,53], it may not solely be a biomarker of oxidative stress because 8 -iso-PGF2 $\alpha$ is also produced by prostaglandinendoperoxide synthases (PGHS)-mediated enzymatic lipid peroxidation [54,55]. Enzymatic lipid peroxidation is significantly induced in inflammation, which can occur as a consequence or stimulator of oxidative stress $[56,57]$. Thus, the fractions of 8 -iso-PGF2 $\alpha$ contributed from chemical lipid peroxidation and enzymatic lipid peroxidation were used to distinguish and quantify the contribution of the two pathways $[18,26,58]$. This method was previously introduced and described in detail by van't Erve et al. [54] and has been supported in an animal model to distinguish biomarker synthesis pathways [55]. Therefore, in this analysis, we additionally examined the hypothesized chemical fraction of 8-iso-PGF $2 \alpha$, which reflects the amount of 8 -iso-PGF $2 \alpha$ attributable to chemical lipid peroxidation, as well as the hypothesized enzymatic fraction of 8 -iso-PGF $2 \alpha$, the amount attributable to inflammation induced enzymatic lipid peroxidation. The fractions were calculated using the ratio of 8 -iso-PGF $2 \alpha$ to PGF $2 \alpha$ as described in detail by van't Erve et al. [54].

\subsection{Statistical Methods}

Metal and oxidative stress biomarker concentrations below the limit of detection (LOD) were replaced by LOD $/ \sqrt{ } 2$. For statistical analysis, we included metal(loid)s with at least $70 \%$ of samples having concentrations above the LOD as continuous variables. Samples with very low detection rates $(<30 \%)$ of metals, including the metals $\mathrm{Be}, \mathrm{Cr}, \mathrm{Ti}, \mathrm{U}$, $\mathrm{V}, \mathrm{Pt}$, and $\mathrm{W}$, were excluded from the analyses. Descriptive statistics were calculated for all exposure and outcome variables. Distributions of all urinary metals and oxidative stress biomarkers were right skewed and, thus, were natural log transformed for all analyses.

We used linear mixed models (LMM) with a random intercept for subject ID to model each prostanoid measure as the dependent variable, with separate models for each exposure biomarker. The crude models included the metal concentration as the exposure and specific gravity as a covariate to adjust for urinary dilution $[48,59,60]$. The final set of covariates were selected based on a priori knowledge and if their inclusion appreciably changed the effect estimates of metal exposure. The covariates considered were study visit, maternal age, insurance type, maternal education level (an indicator of socioeconomic status), marital status, employment status, gravidity, pre-pregnancy body mass index (BMI), smoking, exposure to second-hand smoking, alcohol consumption, and gestational age at the time of sample collection. The final models were controlled for study visit, maternal age, maternal education level, marital status, pre-pregnancy BMI, and exposure to second-hand smoking.

We conducted additional analyses to assess potential windows of vulnerability in pregnancy. We included interaction terms between metal concentrations and each visit indicator separately into the LMMs to obtain visit-specific metal effect estimates. In these separate models the effect estimates of the covariates were still assessed using the whole dataset with the LMM structures rather than a subset of the dataset as in a stratified analysis. Furthermore, we considered the possibility of differential vulnerability among pregnant women carrying a male fetus vs. a female fetus. Therefore, to understand whether the effect estimates for metals on maternal oxidative stress differed according to infant sex, all single-pollutant models were refitted with the addition of an interaction term between metal concentrations and infant sex indicator, and the interaction term coefficient was tested for significance. 
Finally, we used adjusted generalized additive mixed models (GAMM) to graphically depict the relationship between metal concentrations and oxidative stress markers. The results were presented as change in oxidative stress biomarkers ( $95 \%$ confidence intervals per interquartile range (IQR) increase in metal concentrations. We also considered significance after adjusting for multiple testing using the Benjamini-Hochberg method [61]. Since oxidative stress biomarkers were correlated, we calculated $q$ values (adjusted $p$ values) treating each outcome as a family of tests (14 tests per outcome). A cutoff of 0.05 for $q$ value was used to further interpret main results with greater confidence. Data were analyzed using $R$ version 3.6.2 [62].

\section{Results}

\subsection{Demographics}

Demographic characteristics of 215 women in this analysis are summarized in Table 1 and were described previously $[46,63]$. Briefly, the cohort included primarily non-smokers $(81 \%)$ in their late 20 s (median $=27$ years) with half of the women having a BMI less than $25 \mathrm{~kg} / \mathrm{m}^{2}$ prior to pregnancy. The majority of women $(58 \%)$ had private medical insurance and were employed. More than half of them had annual household incomes less than $\$ 30,000$ while $76 \%$ had reported graduating from college or higher. Very few $(6 \%)$ of the women reported consumption of alcohol within the last few months.

Table 1. Demographic characteristics of $n=215$ pregnant women from Puerto Rico.

\begin{tabular}{|c|c|c|}
\hline Variable & \multicolumn{2}{|c|}{ Mean (SD) } \\
\hline maternal age & \multicolumn{2}{|c|}{$26.7(5.5)$} \\
\hline Characteristic & Category & Count (Percent) \\
\hline \multirow{3}{*}{ Insurance type } & private & $124(57.7 \%)$ \\
\hline & public (mi salud) & $80(37.2 \%)$ \\
\hline & missing & $11(5.1 \%)$ \\
\hline \multirow{5}{*}{ maternal education } & $\leq$ high school/ged & $50(23.3 \%)$ \\
\hline & some college or technical school & $73(34 \%)$ \\
\hline & college degree & $64(29.8 \%)$ \\
\hline & master's degree or higher & $26(12.1 \%)$ \\
\hline & missing & $2(0.9 \%)$ \\
\hline \multirow{5}{*}{ household income } & $<\$ 10,000$ & $59(27.4 \%)$ \\
\hline & $\geq \$ 10,000$ to $<\$ 30,000$ & $60(27.9 \%)$ \\
\hline & $\geq \$ 30,000$ to $<\$ 50,000$ & $42(19.5 \%)$ \\
\hline & $\geq \$ 50,000$ & $25(11.6 \%)$ \\
\hline & missing & $29(13.5 \%)$ \\
\hline \multirow{3}{*}{ marital status } & single & $51(23.7 \%)$ \\
\hline & married or living together & $162(75.3 \%)$ \\
\hline & missing & $2(0.9 \%)$ \\
\hline \multirow{4}{*}{ parity (\# birth) } & 0 & $84(39.1 \%)$ \\
\hline & 1 & $77(35.8 \%)$ \\
\hline & $>1$ & $52(24.2 \%)$ \\
\hline & missing & $2(0.9 \%)$ \\
\hline \multirow{3}{*}{ infant sex } & female & $88(40.9 \%)$ \\
\hline & male & $114(53 \%)$ \\
\hline & missing & $13(6 \%)$ \\
\hline \multirow{4}{*}{ prepregnancy BMI $\left(\mathrm{kg} \mathrm{m}^{-2}\right)$} & $\leq 25$ & $105(48.8 \%)$ \\
\hline & $>25$ to $\leq 30$ & $66(30.7 \%)$ \\
\hline & $>30$ & $33(15.3 \%)$ \\
\hline & missing & $11(5.1 \%)$ \\
\hline \multirow{3}{*}{ employment status } & employed & $123(57.2 \%)$ \\
\hline & unemployed & $90(41.9 \%)$ \\
\hline & missing & $2(0.9 \%)$ \\
\hline
\end{tabular}


Table 1. Cont.

\begin{tabular}{ccc}
\hline \multicolumn{2}{c}{ Mariable } & Mean (SD) \\
\hline \multirow{2}{*}{ smoking } & never & $174(80.9 \%)$ \\
& ever & $36(16.7 \%)$ \\
& current & $3(1.4 \%)$ \\
missing & $2(0.9 \%)$ \\
\hline \multirow{2}{*}{ exposure to secondhand } & none & $186(86.5 \%)$ \\
smoking & up to $1 \mathrm{~h}$ & $8(3.7 \%)$ \\
& more than $1 \mathrm{~h}$ & $14(6.5 \%)$ \\
& missing & $7(3.3 \%)$ \\
\hline \multirow{2}{*}{ alcohol consumption } & none & $92(42.8 \%)$ \\
& before pregnancy & $109(50.7 \%)$ \\
& within the last few months & $12(5.6 \%)$ \\
& missing & $2(0.9 \%)$ \\
\hline
\end{tabular}

\subsection{Descriptive Statistics}

Descriptive statistics (geometric mean, geometric standard deviation, select percentiles) of urinary metals and markers of oxidative stress are presented in Table 2. Urinary metals and oxidative stress biomarkers were measured among 215 women in up to three repeated urine samples (visit $1=124$, visit $2=123$, visit $3=91$ ). Spearman correlations between different metals [64] and distribution of oxidative stress markers [18] were previously reported in detail. Briefly, levels of most urinary metals in pregnant Puerto Rican women were higher than levels observed in nonpregnant women ages 18-40 in the general U.S. population [64]. All of the women in our study had essential metal concentrations (Mn and $\mathrm{Zn}$ ) within the normal physiological range $[65,66]$ and none of the non-essential metal concentrations $(\mathrm{Hg}$ and $\mathrm{Pb})$ exceed the level of concern $[67,68]$. A few moderate to strong correlations between urinary metals $(\mathrm{Pb}$ and $\mathrm{Ba}, \mathrm{R}=0.47 ; \mathrm{Cd}$ and $\mathrm{Pb}, \mathrm{R}=0.55, \mathrm{Ni}$ and $\mathrm{Co}, \mathrm{R}=0.55 ; \mathrm{Ni}$ and $\mathrm{Ba}, \mathrm{R}=0.59$ ) were observed. SG-corrected urinary concentrations of metal(loid)s were significantly different between the three visits for $\mathrm{Co}, \mathrm{Cs}, \mathrm{Cu}, \mathrm{Mo}$, and $\mathrm{Zn}(p<0.05$ for all). The geometric mean concentrations of 8-iso-PGF2 $\alpha$ and the 8-isoPGF $2 \alpha$ metabolite were $1.8 \mathrm{ng} / \mathrm{mL}$ and $0.91 \mathrm{ng} / \mathrm{mL}$, respectively, and were moderately correlated (Spearman R $=0.67, p$-value $<0.01$ ). PGF $2 \alpha$ had a geometric mean concentration of $2.8 \mathrm{ng} / \mathrm{mL}$ and was also moderately associated with 8 -iso-PGF2 $\alpha$ (Spearman $\mathrm{R}=0.74$, $p$-value $<0.01$ ) and the 8 -iso-PGF2 $\alpha$ metabolite (Spearman $\mathrm{R}=0.56, p$-value $<0.01$ ).

Table 2. Urinary concentrations of metal(loid)s (ng/mL) and oxidative stress biomarkers (ng/mL) in 215 pregnant women from Puerto Rico ${ }^{1}$.

\begin{tabular}{|c|c|c|c|c|c|c|c|c|c|}
\hline Metal(loid) $^{2}$ & LOD & $\%>$ LOD & GM & GSD & $25 \%$ & $50 \%$ & $75 \%$ & $95 \%$ & $\operatorname{Max}$ \\
\hline $\mathrm{Co}$ & 0.05 & 100 & 1.1 & 1.6 & 0.80 & 1.0 & 1.4 & 2.6 & 8.2 \\
\hline Cs & 0.01 & 100 & 5.4 & 1.4 & 4.3 & 5.3 & 6.6 & 10.0 & 18.4 \\
\hline $\mathrm{Cu}$ & 2.5 & 99.3 & 15.3 & 1.5 & 11.9 & 14.9 & 18.7 & 32.0 & 149 \\
\hline $\mathrm{Mn}$ & 0.08 & 100 & 1.4 & 1.6 & 1.08 & 1.4 & 1.7 & 3.1 & 31.6 \\
\hline Mo & 0.3 & 100 & 61.9 & 1.7 & 44.7 & 63.3 & 84.3 & 147.6 & 307 \\
\hline $\mathrm{Sb}$ & 0.04 & 90 & 0.09 & 1.8 & 0.07 & 0.09 & 0.13 & 0.23 & 1.2 \\
\hline Sn & 0.1 & 100 & 2.0 & 2.6 & 1.0 & 1.7 & 3.2 & 11.2 & 81.4 \\
\hline $\mathrm{Zn}$ & 2 & 100 & 301 & 1.9 & 203 & 327 & 481 & 798 & 2136 \\
\hline As & 0.3 & 100 & 11.3 & 2.2 & 6.6 & 10.9 & 17.8 & 43.1 & 128 \\
\hline $\mathrm{Ba}$ & 0.1 & 99.3 & 2.4 & 2.4 & 1.4 & 2.4 & 4.4 & 10.2 & 35 \\
\hline $\mathrm{Cd}$ & 0.06 & 74.5 & 0.13 & 2.3 & 0.07 & 0.12 & 0.20 & 0.59 & 7.6 \\
\hline $\mathrm{Hg}$ & 0.05 & 98.6 & 0.56 & 2.7 & 0.30 & 0.58 & 1.1 & 2.8 & 13.6 \\
\hline $\mathrm{Ni}$ & 0.8 & 98.9 & 5.1 & 1.7 & 3.8 & 5.2 & 7.1 & 12.3 & 32 \\
\hline $\mathrm{Pb}$ & 0.1 & 72.1 & 0.24 & 2.4 & 0.1 & 0.26 & 0.41 & 1.0 & 4.6 \\
\hline
\end{tabular}


Table 2. Cont.

\begin{tabular}{|c|c|c|c|c|c|c|c|c|c|}
\hline Metal(loid) $^{2}$ & LOD & $\%>$ LOD & GM & GSD & $25 \%$ & $50 \%$ & $75 \%$ & $95 \%$ & Max \\
\hline $\begin{array}{c}\text { Oxidative stress } \\
\text { Biomarkers }^{2}\end{array}$ & & $\%>$ LOD & GM & GSD & $25 \%$ & $50 \%$ & $75 \%$ & $95 \%$ & Max \\
\hline 8-iso-PGF2 $\alpha$ & & 100 & 1.8 & 1.9 & 1.3 & 2.0 & 2.9 & 4.6 & 11.7 \\
\hline 8 -iso-PGF $2 \alpha$ metabolite & & 100 & 0.91 & 1.8 & 0.62 & 0.93 & 1.4 & 2.2 & 7.1 \\
\hline PGF $2 \alpha$ & & 100 & 2.8 & 2.1 & 1.9 & 2.9 & 4.5 & 8.3 & 40.8 \\
\hline
\end{tabular}

${ }^{1}$ Abbreviations: cobalt (Co); cesium (Cs); copper (Cu); manganese (Mn); molybdenum (Mo); antimony (Sb); tin (Sn); zinc (Zn); arsenic (As); barium (Ba); cadmium (Cd); mercury (Hg); nickel (Ni); lead (Pb); limit of detection (LOD); geometric mean (GM); geometric standard deviation (GSD). ${ }^{2}$ Includes specific gravity-corrected urinary metal and oxidative stress biomarkers concentrations for up to three repeated samples per woman $(n=337$ samples, $n=215$ women among which 28 have all three measurements, 66 have two measurements, and 121 have one measurement).

\subsection{Urinary Metals and Prostanoids}

The full models included 314 samples which had complete data on the adjusted covariates (study visit, maternal age, maternal education level, marital status, pre-pregnancy $\mathrm{BMI}$, and exposure to second-hand smoking). Figure 2 presents the associations between urinary metal concentrations and prostanoid markers, and effect estimates, confidence intervals, and $p$ values are also given in Supplemental Table S1.

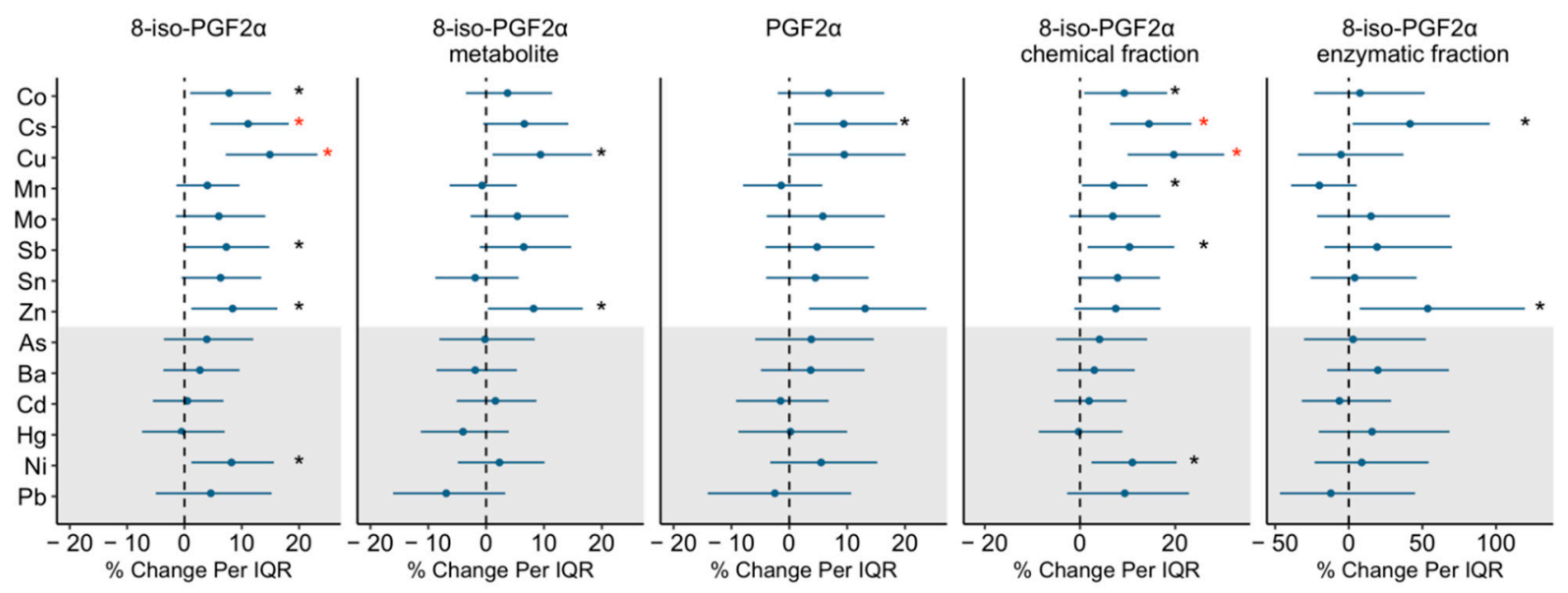

Figure 2. Percent change in prostanoids associated with urinary metal concentrations. Effect estimates presented as percent change (\%) for interquartile range (IQR) increase in exposure biomarker concentration. Models were adjusted for study visit, maternal age, maternal education, marital status, pre-pregnancy BMI, and exposure to secondhand smoking. Abbreviations: cobalt (Co); cesium (Cs); copper (Cu); manganese (Mn); molybdenum (Mo); antimony (Sb); tin (Sn); zinc (Zn); arsenic (As); barium (Ba); cadmium (Cd); mercury $(\mathrm{Hg})$; nickel $(\mathrm{Ni})$; lead $(\mathrm{Pb})$. White shading indicates essential metals and grey shading indicates non-essential metals. Since $\mathrm{Cs}$ is not regarded as essential to the health of plants or animals nor does it present a hazard to them, Cs was considered as essential metal for the analysis. Black * denotes $p$ value $<0.05$; red * denotes a $p$ value $<0.05$ and $q$ value (false discovery rate) $<0.05$.

As presented in Figure 2, the effect estimates from most models on urinary metals were positive. In adjusted models, several urinary metals, including, the essential metals $\mathrm{Co}, \mathrm{Cu}$, and $\mathrm{Zn}$, the non-essential metal $\mathrm{Ni}$, and $\mathrm{Cs}$ and $\mathrm{Sb}$ (not classified as essential or non-essential) were significantly associated with increased 8-iso-PGF2 $\alpha$, the effect estimates ranging from 7.3-14.9\% increased 8-iso-PGF2 $\alpha$ levels per IQR increase in the metal concentration. When we examined these associations for the enzymatic and chemical fractions of 8 -iso-PGF2 $\alpha$, similar significant positive associations remained for the metals and the chemical fraction of 8-iso-PGF2 $\alpha$. The enzymatic fraction of 8-iso-PGF2 $\alpha$ was only associated with Cs (\% $\Delta=41.6,95 \%$ CI: 2.5, 95.7) and Zn (\% $\Delta=53.6,95 \%$ CI: 7.4, 119.6), with wide confidence intervals. Urinary $\mathrm{Cu}$ and $\mathrm{Zn}$ concentrations were also associated 
with 9.4\% (95\% CI: 1.1, 18.3) and 8.2\% (95\% CI: 0.3, 16.7) increases in 8-iso-PGF2 $\alpha$ level, respectively. The IQR increases in Cs and $\mathrm{Zn}$ were associated with a $9.4 \%$ and $13.1 \%$ higher PGF2 $\alpha$ levels (Cs 95\% CI: 0.8, 18.7; Zn 95\% CI: 3.4, 23.7). After adjusting for multiple comparisons, relationships of urinary $\mathrm{Cu}$ and $\mathrm{Cs}$, with 8-iso-PGF2 $\alpha$, as well as the chemical fraction of the 8-iso-PGF2 $\alpha$, remained statistically significant. Results from GAMM including metals concentrations as splines and the GAMM output graphics showed that the observed associations are linear when significant, after adjusting for covariates.

\subsection{Windows of Vulnerability Analysis}

The visit-specific associations between urinary metals and prostanoid markers are shown in Figure 3, and all visit specific estimates, confidence intervals and $p$ values are presented in Supplemental Table S2. The effect estimates were generally in the same direction when comparing the three visits. One exception is that $\mathrm{Ba}$ at visit 3 was negatively associated with 8 -iso-PGF2 $\alpha$ metabolite concentration $(\% \Delta / \mathrm{IQR}=-14.4,95 \% \mathrm{CI}:-24.9$, -2.4 ) while the association was null at visit 1 and 2 . The differences on the effects estimates of Ba between the visits were significant as $p$ value for interaction was 0.04 (visit 3 vs. 1) and 0.03 (visit 3 vs. 2). Although the impact of other urinary metals on oxidative stress did not statistically vary by visits ( $p$ value for interaction $>0.05$ ), a few associations at visit 1 were more robust compared to the other two visits. For example, a significant $20 \%$ and $21 \%$ increase in the chemical fraction of 8-iso-PGF2 $\alpha$ per IQR increase in $\mathrm{Cu}(\% \Delta=19.9$, $95 \%$ CI: $6.5,35.0)$ and $\mathrm{Sb}(\% \Delta=20.6,95 \%$ CI: 6.2, 36.9) at visit 1 were still significant after correction for multiple testing.
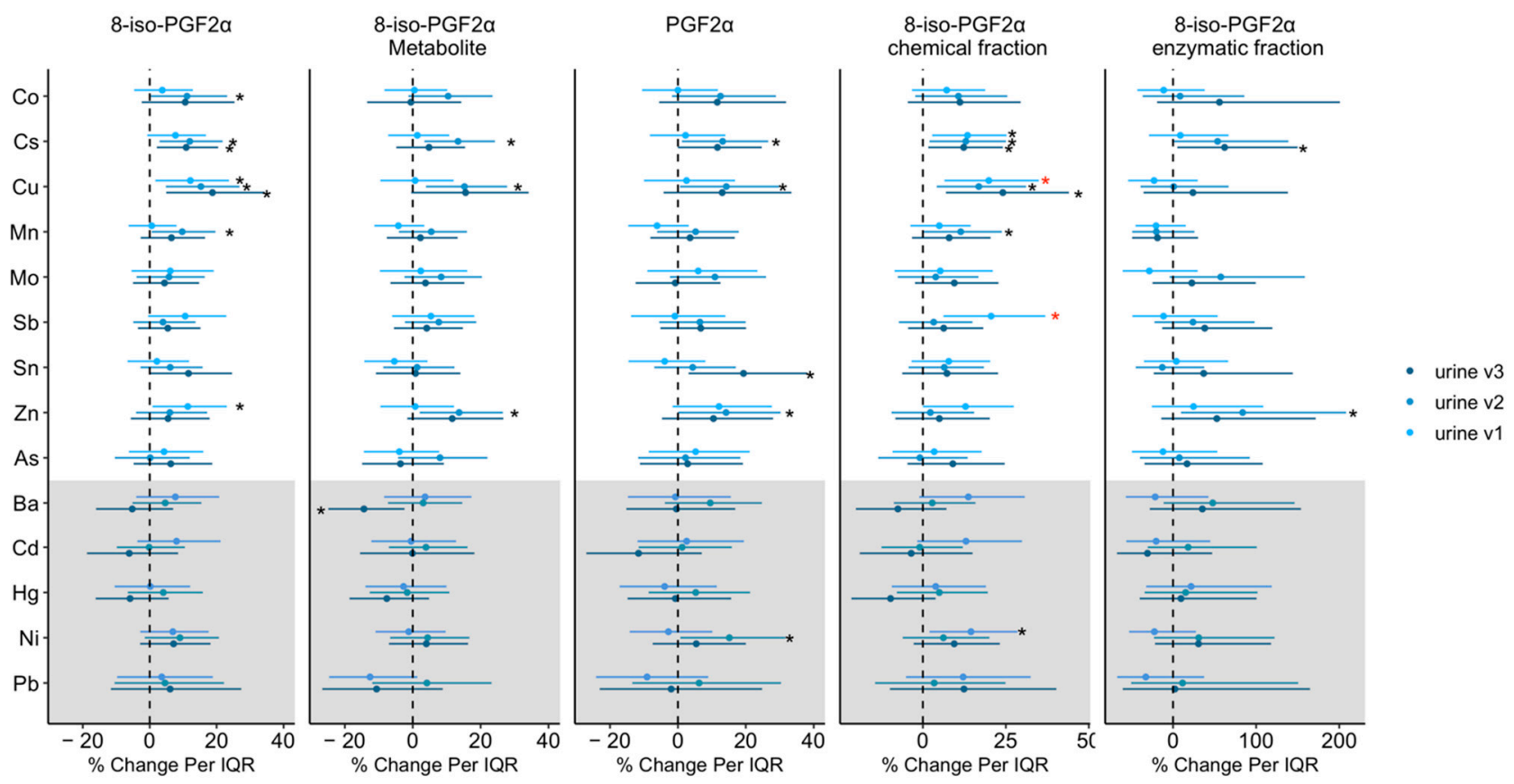

Figure 3. Percent change in prostanoids associated with urinary metal concentrations by study visit. Effect estimates presented as percent changes (\%) for interquartile range (IQR) increase in exposure biomarker concentration. Models were adjusted for study visit, maternal age, maternal education, marital status, pre-pregnancy BMI, and exposure to secondhand smoking. Abbreviations: cobalt (Co); cesium (Cs); copper (Cu); manganese (Mn); molybdenum (Mo); antimony (Sb); tin (Sn); zinc ( $\mathrm{Zn})$; arsenic (As); barium (Ba); cadmium (Cd); mercury (Hg); nickel (Ni); lead (Pb). White shading indicates essential metals and grey shading indicates non-essential metals. Since Cs is not regarded as essential to the health of plants or animals nor does it present a hazard to them, Cs was considered as essential metal for the analysis. Black* denotes $p$ value $<0.05$; red * denotes $p$ value $<0.05$ and $q$ value (false discovery rate) $<0.05$. 


\subsection{Sex-Specific Analysis}

Models with interaction terms between infant sex and metals suggested differences in susceptibility by infant sex for the effects of urinary concentrations of $\mathrm{Co}, \mathrm{Cs}, \mathrm{Cu}$, and $\mathrm{Ni}$ on 8 -iso-PGF2 $\alpha$ (interaction $p$ value $=0.05,0.05,0.02,0.02$ ) and the chemical fraction of the 8 -iso-PGF $2 \alpha$ (interaction $p$ value $=0.03,0.01,0.02,0.01$ ); the associations were only significant among male infants $(p=0.003,<0.001,<0.001,0.001)$ but not female infants $(p=0.71,0.47,0.19,0.99) .14-21 \%$ increases in 8 -iso-PGF2 $\alpha$ associated with one IQR increase in Co $(\% \Delta=14.3,95 \%$ CI: 4.8, 24.6), Cs ( $\% \Delta=14.4,95 \%$ CI: 6.5, 22.9), Cu ( $\% \Delta=21.2,95 \%$ CI: $11.4,31.8)$, and $\mathrm{Ni}(\% \Delta=14.6,95 \% \mathrm{CI}$ : 5.5, 24.4) were observed among women who delivered male infants. Figure 4 depicts the modifying effect of infant sex on the association between these metals and 8-iso-PGF2 $\alpha$. Similar differences were observed for the chemical fraction of 8-iso-PGF2 $\alpha$ (data not shown).

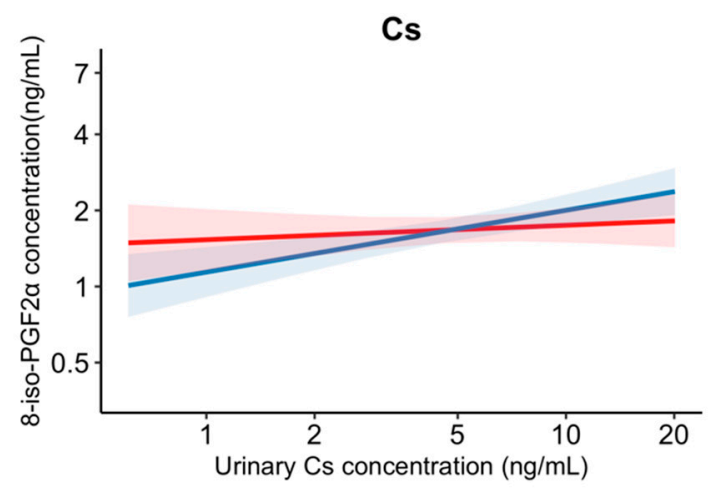

$\mathrm{Cu}$

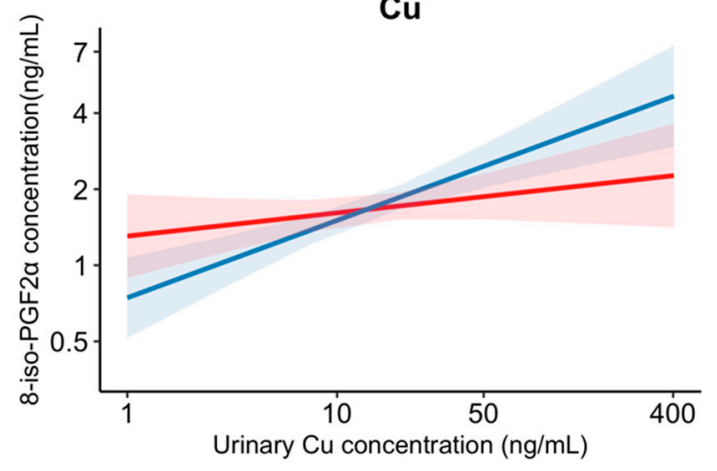

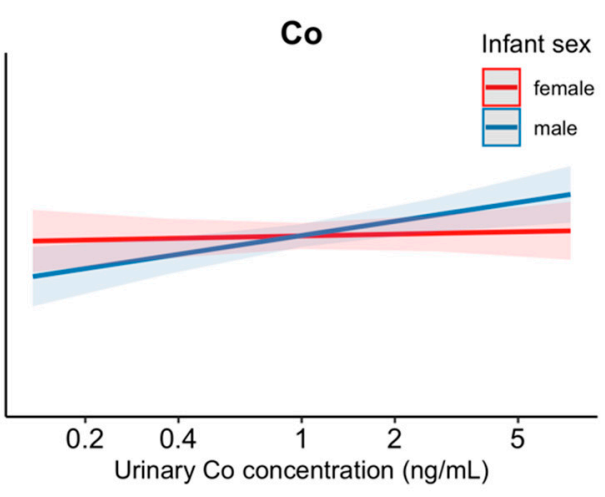

Ni

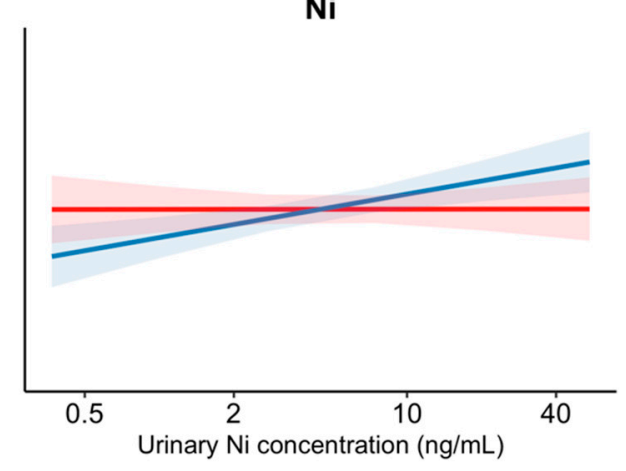

Figure 4. Interaction effect of infant sex on the association between the urinary $\mathrm{Cs}, \mathrm{Co}, \mathrm{Cu}$, and Ni concentration and 8-iso-PGF2 $\alpha$. Models were adjusted for specific gravity, study visit, maternal age, maternal education, marital status, pre-pregnancy BMI, and exposure to secondhand smoking. Abbreviations: cobalt (Co); cesium (Cs); copper (Cu); nickel (Ni). Lines indicate dose-response curve and shading indicates $95 \%$ confidence intervals.

\section{Discussion}

In this study, we evaluated relationships between urinary concentrations of various metal(loid)s and markers of oxidative stress during pregnancy among Puerto Rican women. After accounting for multiple comparisons, the most robust associations found in this study were between urinary $\mathrm{Cs}, \mathrm{Cu}$ and increased 8-iso-PGF2 $\alpha$, respectively, with $15 \%$ and $11 \%$ increases for each IQR increase in $\mathrm{Cs}$ and $\mathrm{Cu}$. The additional analysis of $\mathrm{Cs}$ and $\mathrm{Cu}$ with the fractions thought to reflect 8 -iso-PGF $2 \alpha$ chemical and enzymatic fractions showed that the magnitude and the significance of the associations with the chemical fraction of the 8 -iso-PGF2 $\alpha$ is in concordance with 8 -iso-PGF2 $\alpha$ associations. These findings suggest that the effect of $\mathrm{Cs}$ and $\mathrm{Cu}$ on 8 -iso-PGF2 $\alpha$ may be primarily attributable to the chemical lipid peroxidation pathway. Although the chemical and enzymatic fractions have been hypothesized to distinguish the contribution of 8 -iso-PGF $2 \alpha$ from two pathways, it is worth 
noting that both inflammation or oxidative stress can lead to the changes in the other as they are interrelated $[69,70]$.

Among women in this study, urinary Cs were higher compared to US women aged 18-40 reported from the National Health and Nutrition Examination Survey (NHANES) [64] but lower than the levels reported among pregnant women in Australia and Spain [71,72]. Cs is an alkali metal that naturally occurs in the environment. Typically, human exposure is low, through inhalation of $\mathrm{Cs}$ in the air and/or ingestion of water and food containing Cs [73]. Little is known regarding the health impact of excess Cs exposure. Cs is not regarded as essential to the health of animals or plants, nor is it toxic to them. To our knowledge, no human or animal studies have examined associations between Cs and oxidative stress. However, our findings of urinary Cs associated with higher levels of 8-iso-PGF2 $\alpha$ are in line with plant studies that show Cs can induce the formation of ROS and oxidative stress $[74,75]$. Further studies are needed to assess the mechanisms through which Cs can impact oxidative state in the human body.

Urinary concentrations of $\mathrm{Cu}$ among this population were higher compared to NHANES participants [64], but are within the range reported in previous studies of pregnant women in Australia, Spain, and Japan $[71,76,77]$. Cu plays an essential role in many aspects of human physiology, including acting as cofactor of antioxidant enzymes $[78,79]$. However, cellular toxicity due to oxidative damage has been linked to excess $\mathrm{Cu}$ exposure [80], and some people have increased genetic susceptibility to Cu toxicity (Wilson's Disease) [81]. Consistent with our findings on $\mathrm{Cu}$, a number of animal and human studies found a relationship between elevated $\mathrm{Cu}$ levels and biomarkers of oxidative stress [43,82]. Two different mechanisms have been proposed to explain $\mathrm{Cu}$-induced oxidative damage in the human body: (1) free $\mathrm{Cu}$ can catalyze the formation of hydroxyl radicals-powerful reactive oxygen species (ROS) that can damage cellular DNA, membranes and proteins [42,83,84]; and (2) increased levels of $\mathrm{Cu}$ may suppress the availability of glutathione, a highly abundant cellular antioxidant [85]. Cu was also associated with higher odds of preterm birth in the Puerto Rican population in our study [38] and in a pregnant women cohort in Boston [48], and it is possible that $\mathrm{Cu}$ impacted the early parturition through pathways including oxidative damage.

The window of vulnerability analysis showed positive and robust associations between the chemical fraction of 8-iso-PGF2 $\alpha$ and $\mathrm{Cu}$ and $\mathrm{Sb}$ that are mainly driven by associations in visit 1 (week $18 \pm 2$ of gestation). Metal(loid)s concentrations may vary across pregnancy due to various factors including their unique physiochemical properties and toxicokinetics, the changes in fetal and maternal nutrient supply [86], and the metabolic changes such as variation in glomerular filtration rate $[87,88]$ and plasma volume expansion [89]. We also showed that the timing of the prenatal visit is important for some of the metal(loid)-oxidative stress associations, including an interaction between Ba concentration and prenatal visit in relation to 8 -iso-PGF2 $\alpha$ metabolite concentration. The mechanism underlying the negative association between $\mathrm{Ba}$ and 8-iso-PGF2 $\alpha$ metabolite is unclear as the health effects associated with prenatal $\mathrm{Ba}$ are sparsely investigated in the literature. However, the visit-specific results suggest that gestational age may play a critical role in the association between metal(loid)s and oxidative stress.

Our sensitivity analysis of infant sex-specific effects revealed that associations of metals with oxidative stress markers maybe different between women carrying male or female infants. Urinary $\mathrm{Co}, \mathrm{Cs}, \mathrm{Cu}$, and $\mathrm{Ni}$ concentrations measured among pregnant women who delivered male infants were significantly and positively associated with elevated 8-iso-PGF2 $\alpha$ levels, whereas the associations were null among women who delivered female infants (Figure 3). Although the differential impact of metals on levels of oxidative stress during pregnancy by fetal sex has not been previously reported, the influences of fetal sex on adverse birth outcomes and the health of pregnant women are becoming better understood. Pregnancy with a male fetus has been associated with higher risk of maternal diabetes, pregnancy complications, maternal sympathetic activation, and placental inflammation [90,91]. There is also evidence for a heightened vulnerability to maternal and/or 
environmental exposure for male fetuses compared with female fetuses [92-95]. The sex differential impacts of metals on oxidative stress observed in this study may be attributed, in part, to (1) enzymatic, metabolic, epigenetic differences between male and female fetuses and their interrelation with the maternal environment $[90,96]$ or $(2)$ differences in the hormonal pathways and inflammatory responses involved in mediating effects of infant sex $[97,98]$. Although the biological mechanisms for these well-documented vulnerabilities remain largely unknown and need further investigation, our findings are suggestive of sex differences in the impact of metals on maternal oxidative stress during pregnancy.

Our study is the first to assess the impact of metals on oxidative stress biomarkers among pregnant women in Puerto Rico. The repeated collection of biological samples enabled us to examine the associations with oxidative stress markers at different times during pregnancy which provided greater statistical power to assess longitudinal associations and potential susceptible windows during pregnancy. While most previous studies evaluated total 8-iso-PGF2 $\alpha$ as a biomarker of oxidative stress, we additionally calculated the fraction of chemically-derived 8-iso-PGF2 $\alpha$ and enzymatically-derived fraction of 8iso-PGF $2 \alpha$ to distinguish the contribution of the two pathways. The present study does have some limitations. Oxidative stress biomarkers have short half-lives and the levels change over the course of pregnancy $[99,100]$. However, we did measure markers of both metals and oxidative stress markers at multiple points during pregnancy, increasing the assessment accuracy. While measuring 8-iso PGF2a in the urine provides insight into the systemic state of oxidative stress, it may not represent the redox stress at the placental level where effects from the environmental toxicants may be acting causing preterm birth. Measurement of 8-iso PGF2a at the tissue level may provide more information on the specific oxidative stress occurring here. In this analysis, one of the major assumptions is that metals induce oxidative stress. If oxidative stress causes an increase in urine excretion (i.e., reverse causation), the interpretation of these results would be different. Although this work studied the effect of metals on oxidative stress, other environmental exposures, including phthalates and PAHs, and other mechanisms, such as endocrine disruption, were not explored in this analysis. Future work to investigate the associations between multiple chemical mixture and mechanistic pathways is needed. Additionally, the findings may not be generalizable to other pregnant women populations, considering that the exposure profiles and toxicokinetic of responses to exposure may be quite different compared to pregnant women in Puerto Rico.

\section{Conclusions}

We examined the effect of essential and non-essential metal(loid)s on markers of oxidative stress among pregnant women in Northern Puerto Rico. Results from our study contribute to the growing body of literature suggesting that urinary concentrations of certain metals are associated with elevated levels of oxidative stress during pregnancy, and there is effect modification by fetus sex. This study further highlights the need for future research in this area to examine potential visit-specific and sex-specific effects of environmental exposures on oxidative stress during pregnancy.

Supplementary Materials: The following are available online at https://www.mdpi.com/2076 $-3921 / 10 / 1 / 114 /$ s1, Table S1. Percent change in urinary 8-iso-PGF2 $\alpha, 8$-iso-PGF2 $\alpha$ metabolite, PGF2 $\alpha, 8$-iso-PGF2 $\alpha$ chemical fraction, and 8-iso-PGF2 $\alpha$ enzymatic fraction associated with exposure biomarker concentration, Table S2. Percent change in 8-iso-PGF2 $\alpha, 8$-iso-PGF2 $\alpha$ metabolite, PGF2 $\alpha$, 8 -iso-PGF $2 \alpha$ chemical fraction, and 8-iso-PGF2 $\alpha$ enzymatic fraction associated with urinary metal biomarker concentration at each visit during pregnancy.

Author Contributions: Conceptualization: D.J.W., A.A., J.F.C., and J.D.M.; data curation: Z.R. and C.M.V.-V.; formal analysis: P.A. and G.L.M.; funding acquisition: D.J.W., R.L.-C., A.A., J.F.C., and J.D.M.; investigation: J.D.M.; methodology: P.A., R.L.-C., and J.D.M.; project administration: Z.R. and C.M.V.-V.; software: P.A.; Validation, P.A.; visualization: P.A.; writing-original draft: P.A.; writing-review and editing: D.J.W., K.K.F., R.L.-C., J.F., and J.D.M. All authors have read and agreed to the published version of the manuscript. 
Funding: This research was funded by the Superfund Research Program of the National Institute of Environmental Health Sciences (NIEHS), National Institutes of Health (NIH; grant number P42ES017198). Additional support was provided from NIEHS grant number P30ES017885 and the Environmental influences on Child Health Outcomes (ECHO) program grant number UH3OD023251. ECHO is a nationwide research program supported by the NIH, Office of the Director to enhance child health. Funding for K.K.F. was provided by the Intramural Research Program of NIEHS.

Institutional Review Board Statement: The research protocol for this study was approved by the Ethics and Research Committees of the University of Puerto Rico and participating clinics, the University of Michigan, Northeastern University, and the University of Georgia.

Informed Consent Statement: Informed consent was obtained from all subjects involved in the study.

Data Availability Statement: Data utilized for this analysis can be obtained by reasonable request by contacting both the first author (P.A., pahriya@umich.edu) and the corresponding author (J.D.M., meekerj@umich.edu).

Acknowledgments: We would like to extend our gratitude to all PROTECT study participants and their families. The authors also thank the nurses and research staff who participated in cohort recruitment and follow up, as well as the Federally Qualified Health Centers (FQHC) in Puerto Rico that facilitated participant recruitment, including Morovis Community Health Center, Prymed in Ciales, Camuy Health Services, Inc. and the Delta OBGyn Group in Manati, as well as the Manati Medical Center and the Metro Pavia Hospital in Arecibo.

Conflicts of Interest: The authors declare no conflict of interest.

\section{References}

1. Singh, R.; Gautam, N.; Mishra, A.; Gupta, R. Heavy metals and living systems: An overview. Indian J. Pharmacol. 2011, 43, 246-253. [CrossRef] [PubMed]

2. Diamanti-Kandarakis, E.; Bourguignon, J.P.; Giudice, L.C.; Hauser, R.; Prins, G.S.; Soto, A.M.; Zoeller, R.T.; Gore, A.C. Endocrinedisrupting chemicals: An Endocrine Society scientific statement. Endocr. Rev. 2009, 30, 293-342. [CrossRef] [PubMed]

3. De Coster, S.; van Larebeke, N. Endocrine-disrupting chemicals: Associated disorders and mechanisms of action. J. Environ. Public Health 2012, 2012, 713696. [CrossRef] [PubMed]

4. Mendiola, J.; Moreno, J.M.; Roca, M.; Vergara-Juarez, N.; Martinez-Garcia, M.J.; Garcia-Sanchez, A.; Elvira-Rendueles, B.; Moreno-Grau, S.; Lopez-Espin, J.J.; Ten, J.; et al. Relationships between heavy metal concentrations in three different body fluids and male reproductive parameters: A pilot study. Environ. Health 2011, 10, 6. [CrossRef]

5. Bloom, M.S.; Parsons, P.J.; Steuerwald, A.J.; Schisterman, E.F.; Browne, R.W.; Kim, K.; Coccaro, G.A.; Conti, G.C.; Narayan, N.; Fujimoto, V.Y. Toxic trace metals and human oocytes during in vitro fertilization (IVF). Reprod. Toxicol. 2010, 29, 298-305. [CrossRef] [PubMed]

6. Jones, D.P. Redefining oxidative stress. Antioxid. Redox Signal. 2006, 8, 1865-1879. [CrossRef]

7. Moore, T.A.; Ahmad, I.M.; Zimmerman, M.C. Oxidative Stress and Preterm Birth: An Integrative Review. Biol. Res. Nurs. 2018, 20, 497-512. [CrossRef]

8. Menon, R. Oxidative stress damage as a detrimental factor in preterm birth pathology. Front. Immunol. 2014, 5, 567. [CrossRef]

9. Peter Stein, T.; Scholl, T.O.; Schluter, M.D.; Leskiw, M.J.; Chen, X.; Spur, B.W.; Rodriguez, A. Oxidative stress early in pregnancy and pregnancy outcome. Free Radic. Res. 2008, 42, 841-848. [CrossRef]

10. Sharma, J.; Sharma, A.; Bahadur, A.; Vimala, N.; Satyam, A.; Mittal, S. Oxidative stress markers and antioxidant levels in normal pregnancy and pre-eclampsia. Int. J. Gynecol. Obstet. 2006, 94, 23-27. [CrossRef]

11. Mert, I.; Oruc, A.S.; Yuksel, S.; Cakar, E.S.; Buyukkagnici, U.; Karaer, A.; Danisman, N. Role of oxidative stress in preeclampsia and intrauterine growth restriction. J. Obstet. Gynaecol. Res. 2012, 38, 658-664. [CrossRef]

12. Burton, G.J.; Jauniaux, E. Oxidative stress. Best Pract. Res. Clin. Obstet. Gynaecol. 2011, 25, 287-299. [CrossRef] [PubMed]

13. Ferguson, K.K.; Cantonwine, D.E.; McElrath, T.F.; Mukherjee, B.; Meeker, J.D. Repeated measures analysis of associations between urinary bisphenol-A concentrations and biomarkers of inflammation and oxidative stress in pregnancy. Reprod. Toxicol. 2016, 66, 93-98. [CrossRef] [PubMed]

14. Ferguson, K.K.; Chen, Y.H.; VanderWeele, T.J.; McElrath, T.F.; Meeker, J.D.; Mukherjee, B. Mediation of the Relationship between Maternal Phthalate Exposure and Preterm Birth by Oxidative Stress with Repeated Measurements across Pregnancy. Environ. Health Perspect. 2017, 125, 488-494. [CrossRef] [PubMed]

15. Rosen, E.M.; van 't Erve, T.J.; Boss, J.; Sathyanarayana, S.; Barrett, E.S.; Nguyen, R.H.N.; Bush, N.R.; Milne, G.L.; McElrath, T.F.; Swan, S.H.; et al. Urinary oxidative stress biomarkers and accelerated time to spontaneous delivery. Free Radic. Biol. Med. 2019, 130, 419-425. [CrossRef]

16. Longini, M.; Perrone, S.; Vezzosi, P.; Marzocchi, B.; Kenanidis, A.; Centini, G.; Rosignoli, L.; Buonocore, G. Association between oxidative stress in pregnancy and preterm premature rupture of membranes. Clin. Biochem. 2007, 40, 793-797. [CrossRef] 
17. Mestan, K.; Matoba, N.; Arguelles, L.; Harvey, C.; Ernst, L.M.; Farrow, K.; Wang, X. Cord blood 8-isoprostane in the preterm infant. Early Hum. Dev. 2012, 88, 683-689. [CrossRef]

18. Eick, S.M.; Ferguson, K.K.; Milne, G.L.; Rios-McConnell, R.; Velez-Vega, C.; Rosario, Z.; Alshawabkeh, A.; Cordero, J.F.; Meeker, J.D. Repeated measures of urinary oxidative stress biomarkers and preterm birth in Puerto Rico. Free Radic. Biol. Med. 2020, 146, 299-305. [CrossRef]

19. Valko, M.; Morris, H.; Cronin, M.T. Metals, toxicity and oxidative stress. Curr. Med. Chem. 2005, 12, 1161-1208. [CrossRef]

20. Alfanie, I.; Muhyi, R.; Suhartono, E. Effect of Heavy Metal on Malondialdehyde and Advanced Oxidation Protein Products Cencentration A Focus on Arsenic, Cadmium, and Mercury. J. Med. Bioeng. 2015, 4, 1-6.

21. Betteridge, D.J. What is oxidative stress? Metabolism 2000, 49, 3-8. [CrossRef]

22. Rehman, K.; Fatima, F.; Waheed, I.; Akash, M.S.H. Prevalence of exposure of heavy metals and their impact on health consequences. J. Cell. Biochem. 2018, 119, 157-184. [CrossRef] [PubMed]

23. Singh, L.; Agarwal, P.; Anand, M.; Taneja, A. Toxic and essential metals in placenta and its relation with lipid peroxides/glutathione status in pre-term and full-term deliveries. Asian J. Med. Sci. 2015, 7, 34-39. [CrossRef]

24. Ahamed, M.; Mehrotra, P.K.; Kumar, P.; Siddiqui, M.K. Placental lead-induced oxidative stress and preterm delivery. Environ. Toxicol. Pharmacol. 2009, 27, 70-74. [CrossRef] [PubMed]

25. Quig, D. Cysteine metabolism and metal toxicity. Altern. Med. Rev. 1998, 3, 262-270. [PubMed]

26. Dashner-Titus, E.J.; Hoover, J.; Li, L.; Lee, J.H.; Du, R.; Liu, K.J.; Traber, M.G.; Ho, E.; Lewis, J.; Hudson, L.G. Metal exposure and oxidative stress markers in pregnant Navajo Birth Cohort Study participants. Free Radic. Biol. Med. 2018, 124, 484-492. [CrossRef]

27. Jan, A.T.; Azam, M.; Siddiqui, K.; Ali, A.; Choi, I.; Haq, Q.M. Heavy Metals and Human Health: Mechanistic Insight into Toxicity and Counter Defense System of Antioxidants. Int. J. Mol. Sci. 2015, 16, 29592-29630. [CrossRef]

28. Jaishankar, M.; Tseten, T.; Anbalagan, N.; Mathew, B.B.; Beeregowda, K.N. Toxicity, mechanism and health effects of some heavy metals. Interdiscip. Toxicol. 2014, 7, 60-72. [CrossRef]

29. Andrews, K.W.; Savitz, D.A.; Hertz-Picciotto, I. Prenatal lead exposure in relation to gestational age and birth weight: A review of epidemiologic studies. Am. J. Ind. Med. 1994, 26, 13-32. [CrossRef]

30. Stodden, R.A.; Ianacone, R.N. Career/vocational assessment of the special needs individual: A conceptual model. Except. Child. 1981, 47, 600-608. [CrossRef]

31. Perkins, M.; Wright, R.O.; Amarasiriwardena, C.J.; Jayawardene, I.; Rifas-Shiman, S.L.; Oken, E. Very low maternal lead level in pregnancy and birth outcomes in an eastern Massachusetts population. Ann. Epidemiol. 2014, 24, 915-919. [CrossRef] [PubMed]

32. Torres-Sanchez, L.E.; Berkowitz, G.; Lopez-Carrillo, L.; Torres-Arreola, L.; Rios, C.; Lopez-Cervantes, M. Intrauterine lead exposure and preterm birth. Environ. Res. 1999, 81, 297-301. [CrossRef] [PubMed]

33. Cantonwine, D.; Hu, H.; Sanchez, B.N.; Lamadrid-Figueroa, H.; Smith, D.; Ettinger, A.S.; Mercado-Garcia, A.; Hernandez-Avila, M.; Wright, R.O.; Tellez-Rojo, M.M. Critical windows of fetal lead exposure: Adverse impacts on length of gestation and risk of premature delivery. J. Occup. Environ. Med. 2010, 52, 1106-1111. [CrossRef] [PubMed]

34. Cheng, L.; Zhang, B.; Huo, W.; Cao, Z.; Liu, W.; Liao, J.; Xia, W.; Xu, S.; Li, Y. Fetal exposure to lead during pregnancy and the risk of preterm and early-term deliveries. Int. J. Hyg. Environ. Health 2017, 220, 984-989. [CrossRef] [PubMed]

35. Yang, J.; Huo, W.; Zhang, B.; Zheng, T.; Li, Y.; Pan, X.; Liu, W.; Chang, H.; Jiang, M.; Zhou, A.; et al. Maternal urinary cadmium concentrations in relation to preterm birth in the Healthy Baby Cohort Study in China. Environ. Int. 2016, 94, 300-306. [CrossRef]

36. Wang, H.; Liu, L.; Hu, Y.F.; Hao, J.H.; Chen, Y.H.; Su, P.Y.; Yu, Z.; Fu, L.; Tao, F.B.; Xu, D.X. Association of maternal serum cadmium level during pregnancy with risk of preterm birth in a Chinese population. Environ. Pollut. 2016, 216, 851-857. [CrossRef]

37. Tsuji, M.; Shibata, E.; Morokuma, S.; Tanaka, R.; Senju, A.; Araki, S.; Sanefuji, M.; Koriyama, C.; Yamamoto, M.; Ishihara, Y.; et al. The association between whole blood concentrations of heavy metals in pregnant women and premature births: The Japan Environment and Children's Study (JECS). Environ. Res. 2018, 166, 562-569. [CrossRef]

38. Ashrap, P.; Watkins, D.J.; Mukherjee, B.; Boss, J.; Richards, M.J.; Rosario, Z.; Velez-Vega, C.M.; Alshawabkeh, A.; Cordero, J.F.; Meeker, J.D. Maternal blood metal and metalloid concentrations in association with birth outcomes in Northern Puerto Rico. Environ. Int. 2020, 138, 105606. [CrossRef]

39. Zoroddu, M.A.; Aaseth, J.; Crisponi, G.; Medici, S.; Peana, M.; Nurchi, V.M. The essential metals for humans: A brief overview. J. Inorg. Biochem. 2019, 195, 120-129. [CrossRef]

40. Lewicka, I.; Kocylowski, R.; Grzesiak, M.; Gaj, Z.; Oszukowski, P.; Suliburska, J. Selected trace elements concentrations in pregnancy and their possible role - literature review. Ginekol. Pol. 2017, 88, 509-514. [CrossRef]

41. Jablonska, E.; Vinceti, M. Selenium and human health: Witnessing a Copernican revolution? J. Environ. Sci. Health Part C 2015, 33, 328-368. [CrossRef] [PubMed]

42. Valko, M.; Jomova, K.; Rhodes, C.J.; Kuča, K.; Musílek, K. Redox-and non-redox-metal-induced formation of free radicals and their role in human disease. Arch. Toxicol. 2016, 90, 1-37. [CrossRef] [PubMed]

43. Kim, S.S.; Meeker, J.D.; Keil, A.P.; Aung, M.T.; Bommarito, P.A.; Cantonwine, D.E.; McElrath, T.F.; Ferguson, K.K. Exposure to 17 trace metals in pregnancy and associations with urinary oxidative stress biomarkers. Environ. Res. 2019, 179, 108854. [CrossRef] [PubMed]

44. Cantonwine, D.E.; Cordero, J.F.; Rivera-Gonzalez, L.O.; Anzalota Del Toro, L.V.; Ferguson, K.K.; Mukherjee, B.; Calafat, A.M.; Crespo, N.; Jimenez-Velez, B.; Padilla, I.Y.; et al. Urinary phthalate metabolite concentrations among pregnant women in Northern Puerto Rico: Distribution, temporal variability, and predictors. Environ. Int. 2014, 62, 1-11. [CrossRef] [PubMed] 
45. Meeker, J.D.; Cantonwine, D.E.; Rivera-Gonzalez, L.O.; Ferguson, K.K.; Mukherjee, B.; Calafat, A.M.; Ye, X.; Anzalota Del Toro, L.V.; Crespo-Hernandez, N.; Jimenez-Velez, B.; et al. Distribution, variability, and predictors of urinary concentrations of phenols and parabens among pregnant women in Puerto Rico. Environ. Sci. Technol. 2013, 47, 3439-3447. [CrossRef] [PubMed]

46. Ashrap, P.; Watkins, D.J.; Calafat, A.M.; Ye, X.; Rosario, Z.; Brown, P.; Velez-Vega, C.M.; Alshawabkeh, A.; Cordero, J.F.; Meeker, J.D. Elevated concentrations of urinary triclocarban, phenol and paraben among pregnant women in Northern Puerto Rico: Predictors and trends. Environ. Int. 2018, 121, 990-1002. [CrossRef] [PubMed]

47. Watkins, D.J.; Ferguson, K.K.; Anzalota Del Toro, L.V.; Alshawabkeh, A.N.; Cordero, J.F.; Meeker, J.D. Associations between urinary phenol and paraben concentrations and markers of oxidative stress and inflammation among pregnant women in Puerto Rico. Int. J. Hyg. Environ. Health 2015, 218, 212-219. [CrossRef]

48. Kim, S.S.; Meeker, J.D.; Carroll, R.; Zhao, S.; Mourgas, M.J.; Richards, M.J.; Aung, M.; Cantonwine, D.E.; McElrath, T.F.; Ferguson, K.K. Urinary trace metals individually and in mixtures in association with preterm birth. Environ. Int. 2018, 121, 582-590. [CrossRef]

49. Morales, C.R.; Terry, E.S.; Zackert, W.E.; Montine, T.J.; Morrow, J.D. Improved assay for the quantification of the major urinary metabolite of the isoprostane 15-F(2t)-Isoprostane (8-iso-PGF(2alpha)) by a stable isotope dilution mass spectrometric assay. Clin. Chim. Acta 2001, 314, 93-99. [CrossRef]

50. Morrow, J.D.; Roberts, L.J., 2nd. Mass spectrometric quantification of F2-isoprostanes in biological fluids and tissues as measure of oxidant stress. Methods Enzymol. 1999, 300, 3-12.

51. Milne, G.L.; Sanchez, S.C.; Musiek, E.S.; Morrow, J.D. Quantification of F2-isoprostanes as a biomarker of oxidative stress. Nat. Protoc. 2007, 2, 221-226. [CrossRef]

52. Roberts, L.J.; Morrow, J.D. Measurement of F(2)-isoprostanes as an index of oxidative stress in vivo. Free Radic. Biol. Med. 2000, 28, 505-513. [CrossRef]

53. Awad, J.A.; Morrow, J.D.; Takahashi, K.; Roberts, L.J., 2nd. Identification of non-cyclooxygenase-derived prostanoid (F2isoprostane) metabolites in human urine and plasma. J. Biol. Chem. 1993, 268, 4161-4169. [CrossRef]

54. van 't Erve, T.J.; Lih, F.B.; Kadiiska, M.B.; Deterding, L.J.; Eling, T.E.; Mason, R.P. Reinterpreting the best biomarker of oxidative stress: The 8-iso-PGF(2alpha)/PGF(2alpha) ratio distinguishes chemical from enzymatic lipid peroxidation. Free Radic. Biol. Med. 2015, 83, 245-251. [CrossRef] [PubMed]

55. Van't Erve, T.J.; Lih, F.B.; Jelsema, C.; Deterding, L.J.; Eling, T.E.; Mason, R.P.; Kadiiska, M.B. Reinterpreting the best biomarker of oxidative stress: The 8-iso-prostaglandin F2alpha/prostaglandin F2alpha ratio shows complex origins of lipid peroxidation biomarkers in animal models. Free Radic. Biol. Med. 2016, 95, 65-73. [CrossRef] [PubMed]

56. Basu, S.; Eriksson, M. Lipid peroxidation induced by an early inflammatory response in endotoxaemia. Acta Anaesthesiol. Scand. 2000, 44, 17-23. [CrossRef] [PubMed]

57. Biswas, S.K. Does the interdependence between oxidative stress and inflammation explain the antioxidant paradox? Oxidative Med. Cell. Longev. 2016, 2016, 1-9. [CrossRef] [PubMed]

58. van 't Erve, T.J.; Lih, F.B.; Kadiiska, M.B.; Deterding, L.J.; Mason, R.P. Elevated plasma 8-iso-prostaglandin F2alpha levels in human smokers originate primarily from enzymatic instead of non-enzymatic lipid peroxidation. Free Radic. Biol. Med. 2018, 115, 105-112. [CrossRef]

59. Barr, D.B.; Wilder, L.C.; Caudill, S.P.; Gonzalez, A.J.; Needham, L.L.; Pirkle, J.L. Urinary creatinine concentrations in the U.S. population: Implications for urinary biologic monitoring measurements. Environ. Health Perspect. 2005, 113, 192-200. [CrossRef]

60. Ingle, M.E.; Watkins, D.; Rosario, Z.; VelezVega, C.M.; Calafat, A.M.; Ospina, M.; Ferguson, K.K.; Cordero, J.F.; Alshawabkeh, A.; Meeker, J.D. An exploratory analysis of urinary organophosphate ester metabolites and oxidative stress among pregnant women in Puerto Rico. Sci. Total Environ. 2020, 703, 134798. [CrossRef]

61. Benjamini, Y.; Hochberg, Y. Controlling the false discovery rate: A practical and powerful approach to multiple testing. J. R. Stat. Soc. Ser. B 1995, 57, 289-300. [CrossRef]

62. R Core Team. R: A Language and Environment for Statistical Computing; R Foundation for Statistical Computing: Vienna, Austria, 2017.

63. Aker, A.M.; Ferguson, K.K.; Rosario, Z.Y.; Mukherjee, B.; Alshawabkeh, A.N.; Cordero, J.F.; Meeker, J.D. The associations between prenatal exposure to triclocarban, phenols and parabens with gestational age and birth weight in northern Puerto Rico. Environ. Res. 2019, 169, 41-51. [CrossRef]

64. Ashrap, P.; Watkins, D.J.; Mukherjee, B.; Boss, J.; Richards, M.J.; Rosario, Z.; Velez-Vega, C.M.; Alshawabkeh, A.; Cordero, J.F.; Meeker, J.D. Predictors of urinary and blood Metal(loid) concentrations among pregnant women in Northern Puerto Rico. Environ. Res. 2020, 183, 109178. [CrossRef]

65. Chang, K.L.; Hung, T.C.; Hsieh, B.S.; Chen, Y.H.; Chen, T.F.; Cheng, H.L. Zinc at pharmacologic concentrations affects cytokine expression and induces apoptosis of human peripheral blood mononuclear cells. Nutrition 2006, 22, 465-474. [CrossRef]

66. ATSDR. Toxicological Profile for Manganese; Agency for Toxic Substances and Disease Registry: Atlanta, GA, USA, 2012.

67. CDC. Guidelines for the Identification and Management of Lead Exposure in Pregnant and Lactating Women; National Center for Environmental Health: Washington, DC, USA, 2010.

68. Ye, B.-J.; Kim, B.-G.; Jeon, M.-J.; Kim, S.-Y.; Kim, H.-C.; Jang, T.-W.; Chae, H.-J.; Choi, W.-J.; Ha, M.-N.; Hong, Y.-S. Evaluation of mercury exposure level, clinical diagnosis and treatment for mercury intoxication. Ann. Occup. Environ. Med. 2016, 28. [CrossRef]

69. Basu, S.; Eriksson, M. Oxidative injury and survival during endotoxemia. FEBS Lett. 1998, 438, 159-160. [CrossRef] 
70. Basu, S. Oxidative injury induced cyclooxygenase activation in experimental hepatotoxicity. Biochem. Biophys. Res. Commun. 1999, 254, 764-767. [CrossRef]

71. Fort, M.; Cosin-Tomas, M.; Grimalt, J.O.; Querol, X.; Casas, M.; Sunyer, J. Assessment of exposure to trace metals in a cohort of pregnant women from an urban center by urine analysis in the first and third trimesters of pregnancy. Environ. Sci. Pollut. Res. Int. 2014, 21, 9234-9241. [CrossRef]

72. Hinwood, A.L.; Stasinska, A.; Callan, A.C.; Heyworth, J.; Ramalingam, M.; Boyce, M.; McCafferty, P.; Odland, J.O. Maternal exposure to alkali, alkali earth, transition and other metals: Concentrations and predictors of exposure. Environ. Pollut. 2015, 204, 256-263. [CrossRef]

73. ATSDR. Toxicological Profile for Cesium; Agency for Toxic Substances and Disease Registry: Atlanta, GA, USA, 2004.

74. Atapaththu, K.S.; Rashid, M.H.; Asaeda, T. Growth and Oxidative Stress of Brittlewort (Nitella pseudoflabellata) in Response to Cesium Exposure. Bull. Environ. Contam. Toxicol. 2016, 96, 347-353. [CrossRef]

75. Sahr, T.; Voigt, G.; Paretzke, H.G.; Schramel, P.; Ernst, D. Caesium-affected gene expression in Arabidopsis thaliana. New Phytol. 2005, 165, 747-754. [CrossRef]

76. Callan, A.C.; Hinwood, A.L.; Ramalingam, M.; Boyce, M.; Heyworth, J.; McCafferty, P.; Odland, J.O. Maternal exposure to metals-concentrations and predictors of exposure. Environ. Res. 2013, 126, 111-117. [CrossRef]

77. Shirai, S.; Suzuki, Y.; Yoshinaga, J.; Mizumoto, Y. Maternal exposure to low-level heavy metals during pregnancy and birth size. J. Environ. Sci. Health Part A 2010, 45, 1468-1474. [CrossRef]

78. Uauy, R.; Olivares, M.; Gonzalez, M. Essentiality of copper in humans. Am. J. Clin. Nutr. 1998, 67, 952S-959S. [CrossRef]

79. Turnlund, J. Copper nutriture, bioavailability, and the influence of dietary factors. J. Am. Diet. Assoc. 1988, 88, 303-308.

80. Gaetke, L.M.; Chow, C.K. Copper toxicity, oxidative stress, and antioxidant nutrients. Toxicology 2003, 189, 147-163. [CrossRef]

81. ATSDR. Toxicological Profile for Copper; Agency for Toxic Substances and Disease Registry: Atlanta, GA, USA, 2004.

82. Thounaojam, T.C.; Panda, P.; Mazumdar, P.; Kumar, D.; Sharma, G.; Sahoo, L.; Sanjib, P. Excess copper induced oxidative stress and response of antioxidants in rice. Plant Physiol. Biochem. 2012, 53, 33-39. [CrossRef]

83. Bremner, I. Manifestations of copper excess. Am. J. Clin. Nutr. 1998, 67, 1069S-1073S. [CrossRef]

84. Kadiiska, M.B.; Hanna, P.M.; Jordan, S.J.; Mason, R.P. Electron spin resonance evidence for free radical generation in copper-treated vitamin E-and selenium-deficient rats: In vivo spin-trapping investigation. Mol. Pharmacol. 1993, 44, $222-227$.

85. Jomova, K.; Baros, S.; Valko, M. Redox active metal-induced oxidative stress in biological systems. Transit. Met. Chem. 2012, 37, 127-134. [CrossRef]

86. King, J.C. Physiology of pregnancy and nutrient metabolism. Am. J. Clin. Nutr. 2000, 71, 1218S-1225S. [CrossRef]

87. Weaver, V.M.; Vargas, G.G.; Silbergeld, E.K.; Rothenberg, S.J.; Fadrowski, J.J.; Rubio-Andrade, M.; Parsons, P.J.; Steuerwald, A.J.; Navas-Acien, A.; Guallar, E. Impact of urine concentration adjustment method on associations between urine metals and estimated glomerular filtration rates (eGFR) in adolescents. Environ. Res. 2014, 132, 226-232. [CrossRef]

88. Cheung, K.L.; Lafayette, R.A. Renal physiology of pregnancy. Adv. Chronic Kidney Dis. 2013, 20, 209-214. [CrossRef]

89. Hytten, F.E.; Paintin, D.B. Increase in plasma volume during normal pregnancy. J. Obstet. Gynaecol. Br. Emp. 1963, 70, 402-407. [CrossRef]

90. Al-Qaraghouli, M.; Fang, Y.M.V. Effect of Fetal Sex on Maternal and Obstetric Outcomes. Front. Pediatr. 2017, 5, 144. [CrossRef]

91. DiPietro, J.A.; Voegtline, K.M. The gestational foundation of sex differences in development and vulnerability. Neuroscience 2017, 342, 4-20. [CrossRef]

92. Fontaine, C.J.; Patten, A.R.; Sickmann, H.M.; Helfer, J.L.; Christie, B.R. Effects of pre-natal alcohol exposure on hippocampal synaptic plasticity: Sex, age and methodological considerations. Neurosci. Biobehav. Rev. 2016, 64, 12-34. [CrossRef]

93. Jedrychowski, W.; Perera, F.; Mrozek-Budzyn, D.; Mroz, E.; Flak, E.; Spengler, J.D.; Edwards, S.; Jacek, R.; Kaim, I.; Skolicki, Z. Gender differences in fetal growth of newborns exposed prenatally to airborne fine particulate matter. Environ. Res. 2009, 109, 447-456. [CrossRef]

94. Wolff, M.S.; Engel, S.M.; Berkowitz, G.S.; Ye, X.; Silva, M.J.; Zhu, C.; Wetmur, J.; Calafat, A.M. Prenatal phenol and phthalate exposures and birth outcomes. Environ. Health Perspect. 2008, 116, 1092-1097. [CrossRef]

95. Cowell, W.J.; Wright, R.J. Sex-specific effects of combined exposure to chemical and non-chemical stressors on neuroendocrine development: A review of recent findings and putative mechanisms. Curr. Environ. Health Rep. 2017, 4, 415-425. [CrossRef]

96. Aiken, C.E.; Ozanne, S.E. Sex differences in developmental programming models. Reproduction 2013, 145, R1-R13. [CrossRef]

97. Murphy, V.E.; Smith, R.; Giles, W.B.; Clifton, V.L. Endocrine regulation of human fetal growth: The role of the mother, placenta, and fetus. Endocr. Rev. 2006, 27, 141-169. [CrossRef]

98. Clifton, V.L. Review: Sex and the human placenta: Mediating differential strategies of fetal growth and survival. Placenta 2010, 31, S33-S39. [CrossRef]

99. Basu, S. Review isoprostanes: Novel bioactive products of lipid peroxidation. Free Radic. Res. 2004, 38, 105-122. [CrossRef]

100. Morris, J.M.; Gopaul, N.K.; Endresen, M.J.; Knight, M.; Linton, E.A.; Dhir, S.; Ängård, E.E.; Redman, C.W. Circulating markers of oxidative stress are raised in normal pregnancy and pre-eclampsia. BJOG Int. J. Obstet. Gynaecol. 1998, 105, 1195-1199. [CrossRef] 